\title{
Dietary and Immunomodulatory Measures for Boosting Immunity to Fight Covid-19
}

\author{
M. Shavina Devi and Swaroopa Chakole \\ Department of Community Medicine, Jawaharlal Nehru Medical College, Datta Meghe Institute of \\ Medical Sciences (Deemed to be University), Sawangi (Meghe), Wardha-442001, India \\ Corresponding author email: drswaroopachakole@gmail.com
}

\section{ABSTRACT}

The deadly nature and huge case fatality rate in COVID-19 is now established by figures that are coming out daily. Various trends and symptoms are being unfurled by the pandemic and researchers are constantly trying to study them. One of the trends that is solidly established is that comorbid patients with COVID-19 infection have higher chances of developing severe symptoms and needs critical care attention in order to overcome the disease. Dietary pattern was less talked about aspect of the health paradigm but it has great influence on the physical and mental wellbeing of the individual. The trends towards high fat, carbohydrate, sugar food is really worsening and can be an invitation to chronic and terminal diseases like diabetes, cancer, COPD and many more if not checked in time. Gut microbiota has a crucial role in maintaining the homeostasis of the immunity system. Difference of diet in developed and developing countries is reason for more case fatality rates in developed countries despite having better health infrastructure than their developing counterparts. Gut microbiota also differs in these two geographically different regions. Role of immunity boosting and building diet is immense in preventive as well as curative aspect of COVID-19. Various vitamins and probiotics have profound effects on innate immune response system of the body. Infodemic is also a parallel emergency that is essential to address as prescribed medications can prove very harmful. This article tries to take a holistic review of these aspects.

\section{KEY WORDS: DIET,COVID-19, PROPHYLAXIS, VITAMIN C, VITAMIN D, TREATMENT, COMPLICATIONS.}

\section{INTRODUCTION}

Coronavirus disease 2019 or COVID-19 is the deadliest pandemic that world has ever seen in last several decades. Even its previous outbreaks of severe acute respiratory syndrome (SARS) and Middle Eastern respiratory syndrome (MERS) were not as devastating as this one. (Dushyant et a;., 2020) From its inception and emergence from Wuhan city of Hubei Province of china, it spread all over the world and grappled every habited country. SO far till December 12, 2020, 69,521,294 (2) confirm cases of COVID-19 patients were registered and 1,582,674 deaths

Biosc Biotech Res Comm P-ISSN: 0974-6455 E-ISSN: 2321-4007

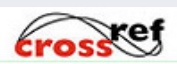

Identifiers and Pagination

Year: 2021 Vol: 14 No (6) Special Issue

Pages: 180-185

This is an open access article under Creative

Commons License Attribn 4.0 Intl (CC-BY).

DOI: $h t t p: / / d x . d o i . o r g / 10.21786 / b b r c / 14.6 .39$ due to COVID-19 are registered. United States of America, Brazil, India and Russia are top four countries (Butler 2020) that are currently harboring most cases.

The ability to spread superfast and proving deadly makes this virus more feared. Almost after a year when it struck, changes from its viral strain to symptoms were observed. As no previous history was available about the disease, the containment plan was implemented on trial-anderror basis. The initial hiccups and blanket restrictions on movement kept figures low but not for long time. As the restrictions got eased up the case numbers shot up and the health care facilities were overwhelmed, it was difficult for the hospital administration to accommodate all of the patients and delayed medical intervention had also contributed to the case fatality rate. Several trends are being established like elderlies and pregnant women are more vulnerable than any other section of the human society.

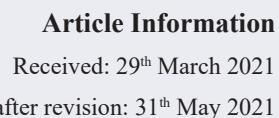

ccepted after revision: $31^{\text {th }}$ May 2021

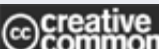
creative 
Also, comorbidity and unhealthy eating habits in western and developed countries particular of junk food are seriously worsening the over health and immune response mechanism of the body( Guan et al., 2020). That loophole is precisely exploited by the coronavirus. Weaker the host, stronger is the coronavirus and more is the damage done by it. Dietary pattern was less talked about aspect of the health paradigm but it has great influence on the physical and mental wellbeing of the individual. The trends towards high fat, carbohydrate, sugar food is really worsening and can be an invitation to chronic and terminal diseases like diabetes, cancer, COPD and many more if not checked in time. Gut microbiota has a crucial role in maintaining the homeostasis of the immunity system.

Difference of diet in developed and developing countries is reason for more case fatality rates in developed countries despite having better health infrastructure than their developing counterparts. Gut microbiota also differs in these two geographically different regions. Role of immunity boosting and building diet is immense in preventive as well as curative aspect of COVID-19. Various vitamins and probiotics have profound effects on innate immune response system of the body. Infodemic is also a parallel emergency that is essential to address as prescribed medications can prove very harmful. In this article we are going to take a holistic review of these aspects.

Comorbidity, Dietary Pattern and Covid-19: The deadly nature and huge case fatality rate (CFR) of and in COVID19 is now established by figures that are coming out daily. Various trends and symptoms are being unfurled by the pandemic and researchers are constantly trying to study them. One of the trends that is solidly established is that comorbid patients with COVID-19 infection have higher chances of developing severe symptoms and needs critical care attention in order to overcome the disease. Comorbidity(Wang et al., 2020), elderlies and pregnant women are three of the most vulnerable section of the human population that are prone to COVID-19 than others. Underlying medical conditions such as diabetes, hypertension, renal disorder, heart ailment etc. are some of the disease that can prove fatal if it combines with COVID-19 infection.

Obesity which is on rise due to consumption of junk food also is the prime reason for rising case fatality rate among population of developed countries. The huge case fatality rate that is being observed worldwide and not seen in other disease or viral outbreak in past hundred years is certainly attributed to the old age and comorbidity. These two factors basically wane away the innate immune response systems power to combat the deadly infection. This together with crumbling health care infrastructure (Sahoo et al., 2020) has proven unfortunate to this section of the population. The pandemic was followed by blanket measures like lockdown and physical distancing which kept people confined to home. There is a stark variation in the diet of the people particularly urban residents.
Eating anytime, irregular and over eating, irregular sleeping and lack of exercise are seriously taking toll on the body and can reduce the immunity power of the body. Work life balance is disturbed as people are virtually on work all day. Screen time has been increased and craving for high carbohydrate and high fats and sugar food is on all-time high. Movement restrictions are hindering with the exercise pattern and most of the time people either sitting or eating. This lifestyle can lead to various chronic disease such as diabetes, heart ailments which may prove fatal not in the long term but in current pandemic time too.

Immunity Building Diet in Covid-19 Pandemic: There is lot buzz around certain types of food being more helpful than others to build the immune system of the body. There are two types of immunity. Innate immunity and acquired immunity. Innate immunity or innate immune response is genetically inherited and is carried right from the birth. Whereas the acquired immunity, as the name suggests, is taken up and built upon throughout the life. This can through vaccination and other medication. Innate response is the first responder when external pathogen tries to harm the inner functioning of the body. So, when it becomes weak, we have to take medications to fight the infection. Certain food components in our diet are meant to build and makes stronger this system. If taken properly according to contraindications, it can benefit the body and can act as prophylactics particularly in times of pandemic where prevention way better than cure.

Vitamin C, Vitamin D, zinc etc. are the components that are proven to be beneficial to the overall wellbeing of the body. Foods containing these substances and fortified medicines also can help in absorbing these important factors in our body. Vitamin C( Feyaerts et al., 2020) is the most widely used food substance for immunity building properties. Citrus fruits like lemons, oranges, apples etc. are found to be containing good amount of vitamin $\mathrm{C}$. Also, some vegetables like brinjal, beetroot, spinach, cauliflower contains vitamin -C. Extract of curcumin in liquid form and spirulina which are loaded with vitamin c are some of the over-the-counter medications. In fact, they are the best source of antioxidants which are regularly required by our body. Vitamin C is supposed to be reduce inflammation inside our body and which is the prime concern in COVID-19 disease.

In addition, the constant oxidative stress generated by the body plus unhealthy diet can increase the chances of weakening immunity. Vitamin $\mathrm{C}$ is meant to be reduce oxidative stress of the body and contain the inflammatory tissues. Certain medication protocols being used currently have vitamin $\mathrm{C}$ tablets in their medicinal course but any use must be certified and approved by the concerned agencies. Vitamin c is particularly benefitting in shortening the duration of cough and cold which are one of the symptoms of COVID-19. Some studies also highlighted the benefits provided by the vitamin $\mathrm{c}$ in pneumonia. Also, a mild to severe symptom of the COVID-19 (Benarba t al., 2020). 
Vitamin D (Malek 2020) is yet another such vitamin which possibly helps in containing the COVID-19. Vitamin D in general is needed by the body to absorb calcium, strengthening bone and teeth. Major portion of the vitamin D requirement of the body comes from exposure to the sun. Foods that includes vitamin D includes oily fishes such as salmon, herring etc., red meat, egg yolks and some fortified foods. It helps to regulate the calcium and phosphorus levels of the body which are needed to keep muscles, teeth's, and bones in good condition. Lack of Vitamin D causes rickets, deformation of bones, brittle bones et cetera. Major portion as earlier said comes from sun's exposure to skin which in turn generates vitamin $d$. But due to non-pharmacological interventions like lockdowns and physical distancing and fear of contracting the COVID-19 made people stay at home.

Their exposure time were reduced and naturally they are more prone to deficiency of vitamin D. Also, its role in innate and adaptive immunity response is already established. Vitamin D is also supported the binding of ACE2( Bourgonje et al., 2020) (Angiotensin converting enzyme 2) to AGTR1 (receptor type 1) which in turns makes difficult for Severe acute respiratory syndrome coronavirus 2 to attach and find the host cell which then it takes control of and severely disturbs the protein synthesis. One study conducted on 780 individuals who were tested positive for COVID-19 highlights the relation between levels of vitamin D and severity of the symptoms of COVID-19. Among the pool of positive patients, elderlies and persons developed severe symptoms were found to be vitamin $\mathrm{D}$ deficient. It also depends on seasons as now northern part of the earth is experiencing winter and southern part is more tilted towards sun so the levels in blood of vitamin $\mathrm{D}$ would be less and more respectively.

This can also be used in strategizing according to the geographical locations of the country. Though good sunlight only does not guarantee any protection from vitamin D deficiency as the body needs to be exposed to the sun. It has also a psychological effect which enhances the moods of the person. Fortification of the food with Vitamin D (Ali et al., 2020) can be done and distributed as a prophylactic with taking proper care for contraindications. Especially when the health care infrastructure is overwhelmed with lots of patients and there is less space to accommodate all of them, it is important to prevent the disease from happening than seeking curative measures post contraction. It will take care of vitamin D deficiency and also be used by the body to boost the immunity. Minimum necessary early morning exposure to the sun regularly can also be beneficial. As the non-pharmacological interventions (NPI) like lockdowns and physical distancing are easing up, one can make sure they are taking adequate amount of Vitamin D( Pizzini et al., 2020).

Vitamin E (Infusino, et al.,2020) also have some preventive and curative properties like other vitamins and minerals. These are essential requirement of the body to maintain physical and mental wellbeing of the body. Vegetable oils such as soybean oil, sunflower oil, almonds, peanuts, green leafy vegetables are the foods which contains vitamin E. It has varied range of benefits such as in cholesterol levels, as antioxidants. It is found that it can be given as prophylactic in COVID-19 pandemic. But under strict supervision of the doctors. As it is fat soluble vitamin it has to be taken in limited quantity. Also, not all persons need supplementary forms like capsules and tablets which are more concentrated forms rather it should be absorbed by the body through foods itself.

Vitamin E is supposed to be generate strong antibody response which is particularly beneficial in COVID-19 pandemic. Zinc( Arshad et al., 2020) plays an important role in cell division, cell growth, wound healing etc. It is also found out that like in Vitamin D some studies implied that COVID-19 infected patients have low level of zinc in their blood samples. Probiotics are also good tool for immunity building which are generally taken in rich families as they are quite expensive. Cheaper alternative needs to be produced so that it can also be ingested by all section of the society. Probiotics are meant to be exhibits several beneficial activities in host cell particularly in viral infection.

Probiotics (Sundararaman et al., 2020) can be a game changer in elder population as they are having weak immunity period in their life. The mortality rate is not high in general population but when scrutinized in age wise differentiation, population of age greater than 50 have more suffered than any other group of population. Because of their weak immune system and inability to extract all the benefits from their food. Also, in hospitalized patients where they are prone to ventilator induced pneumonia. This risk of pneumonia can be vastly reduced by the administration of probiotics to them. In children's the chances of developing respiratory tract infection is greatly reduced by the probiotics. (Jayawardena 2020) Probiotics excludes the pathogens that re not good for the human body and colonize the gut itself to maintain the gut health.

Lifestyle, Gut Microbiota and Covid-19: One stark difference was noted in casualties in western countries and countries like India is that the case rate and case fatality rate was extremely high meaning death per positive for COVID-19 people was extremely high in countries like Italy, Spain, Brazil, United States of America etc. whereas in the countries like the positivity rate is quite high but the case fatality rate is remarkably low as compared to the previously mentioned countries. This is largely attributed to the eating habits and the lifestyle of these two countries. Also, gut biota is being said to playing the role of immunity booster in the body. The habit of junk food eating in western countries and high meat intake which in turn results into high saturated fats and sugar intake already started to worsen the condition of the body. 
Further excessive alcoholism and consumption of psychedelic substances are on rise in those countries. Whereas in countries like India where population is largely consumes vegetarian products and there is less trend of alcoholism and consumption of drugs may have resulted in less number case fatality rate in these countries. Lifestyle in COVID-19, already is the issue due to sedentary lifestyle, is a cause of concern. The lockdown and in turn home confinement induced by the COVID19 further contributing in degrading the situation. The sedentary lifestyle percolated to all sections of society for long enough that it feared to forming such habits. Comorbidity or underlying medical illnesses that are chronic and takes decades to be resolved or not be resolve at all such as cancer, diabetes, heart ailments, digestive disorders are all the results of lifestyle changes that are occurring due to sitting nature of work.

Lack of physical exercise and improper diet containing high carbohydrates, fats, sugars are inviting the aforementioned diseases. It is necessary to look these lifethreatening lifestyle changes to be addressed in order to future ready. As WHO already warned that COVID-19 is not the last pandemic(18) that struck the humanity in 20 th century but there can be another so one must be ready to face such kind of health disaster. Maintaining over health good is only possible through balance diet and physical and mental exercises. Sustainable and inclusive health should be our motto of our every policy so that it gets proper attention. As a matter of comparison in developed and in developing countries former has way less fiber content in their foods than developing ones.

As we know fiber helps to flush out the toxins out of the body and keeps waste material together to eject them. Diversity in gut microbiome is also necessary and previous trend of developed countries lacking than developing ones continues here too. Prevotellas and xylanibactor (Rishi et al., 2020) were found to be in great amount in gut microbiota of Indian people who largely consume plant-based diet and which are essential for digesting some otherwise indigestible substances like complex polysaccharides. Several other probiotics were found to be present in vegetarian diet consuming population which are good in nature. There is also urban-rural divide in terms of good gut bacteria that are essential in proper digestion. Studies found out that rural population which consumes more fiber rich diet have more strong digestive systems than the urban population. This shows how dietary habits can influence the immunity and overall digestive health of the person. But taking medications at random can prove lethal.

As the Infodemic is ongoing alongside pandemic, one needs to be cautious while trusting any unauthorized message. As various misinforming messages are circulating and creating another health menace. Cross checking the message before implementing should be the standard operating procedure while dealing with any suspicious information. Many messages are suggesting wrong and false information about the proposed treatment of the COVID-19 (Jachak et al., 2020; Joshi, et al., 2020; Khatib et al., 2020). Biswas et. al. recommended dietary and living regimen of covid-19 with special reference to Ayurveda (Gaidhane 2020).

Many studies on boosting immunity during COVID pandemic were reported . (Rathi et. al., 2020) recommended Chyavanprash as the choice of drug for immunity boosting and health supplements during COVID-19 Pandemic. Similar studies were reported by (Bhokardankar et. al., 2020; Bhutada et. al., 2020). Reviews by (Dhok et. al., 2020; Dasari et.al., 2020; Kolhe et.al. 2020) reflected a few key aspects regarding immunity boosting. Many stating several doctors name on it to make them look authenticate. But it has severe repercussions in terms of health of the concern person. Consultation with the doctor is necessary before trying any self-medication.

\section{CONCLUSION}

Comorbidity is established to be the most decisive factor in deciding the severity of the disease and the course of the treatment. Due to the huge number of patients the health care infrastructure is already overwhelmed. Therefore, it is necessary to prevent the disease from happening than curing it. Supplementary diet can be he game changer in terms of lowering the case number itself. Vaccine trials are in their final leg but its administration and its efficacy with observing any allergic reaction will take while to go. Supplementary diet can be very effective in building the innate immune response to the level up to which it can tackle the attack of external pathogen like coronavirus. Changes in dietary pattern are necessary in order to inculcate the fiber and protein rich food. Foods like vitamin c, vitamin d, probiotics needs to be studied more to find the correlation between its efficacy in COVID-19 and its dosage.

Elderly which are more prone to the aforementioned disease should be administer such prophylactics in order to lessen the burden on health care infrastructure. In far flung areas, fortification of foods can be the solution. Developed countries can adopt the diet from developing countries as gut bacteria was found to be healthier in later regions. Infodemic needs to be tackled with same speed and vigor as itself to avoid any misinformation to be circulated. People and governments with nongovernmental organizations have to tackle and prevent another pandemic to deepen its roots. As the saying goes that we are what we eat. We have to make our lifestyle healthier and physically active in order to be resilient in the time of crisis. By that way we can be future ready for any such worst health scenario because COVID-19 is not the last pandemic that has struck the humanity.

\section{REFERENCES}

Ali N. Role of vitamin D in preventing of COVID-19 infection, progression and severity. J Infect Public Health https://www.ncbi.nlm.nih.gov/pmc/articles/ PMC7305922/

Arshad MS, Khan U, Sadiq A, Khalid W, Hussain M, Yasmeen A, et al. 2020 Coronavirus Disease (COVID-19) 
and Immunity Booster Green Foods: A Mini Review. Food Sci Nutr. 31;21-29

Benarba B, Gouri A. 2020 Pre-exposure and Postexposure new prophylactic treatments against COVID19 in healthcare workers. 22;260-7.

Bhokardankar, P., B. Rathi, M. Khan, and R. Rathi. 2020 "COVID-19 Pandemic: Home Remedies for Immunity Boosting." International Journal of Research in Pharmaceutical Sciences 11: 734-38. https://doi. org/10.26452/ijrps.v11iSPL1.3075.

Bhutada, R.S., R. Rathi, and D. Dasar. 2020 "Immunity Boosting Diet during COVID 19.” International Journal of Research in Pharmaceutical Sciences 11:832-38. https://doi.org/10.26452/ijrps.v11iSPL1.3089.

Biswas, A., and K. Chandankhede. 2020 "Dietary and Living Regimen of COVID-19 with Special Reference to Ayurveda Varsha and Sharad Ritucharya." International Journal of Research in Pharmaceutical Sciences 11: 758-62. https://doi.org/10.26452/ijrps.v11iSPL1.3079. Boharupi, G., and P. Shelotkar. 2020 "Immunomodulatory Measures to Strengthen the Body during Covid Outbreak." International Journal of Research in Pharmaceutical Sciences 11: 774-78. https://doi. org/10.26452/ijrps.v11iSPL1.3081.

Bourgonje AR, Abdulle AE, Timens W, Hillebrands J, Navis GJ, Gordijn SJ, et al. 2020 Angiotensin converting enzyme 2 (ACE2), SARS-CoV-2 and pathophysiology of coronavirus disease 2019 (COVID-19). J Pathol https:// www.ncbi.nlm.nih.gov/pmc/articles/PMC7276767/ Butler MJ, Barrientos RM. 2020 The impact of nutrition on COVID-19 susceptibility and long-term consequences. Brain Behav Immun https://www.ncbi. nlm.nih.gov/pmc/articles/PMC7165103/

Chaple, J.N. "Ayurveda and Vyadhikshamatwa (Immunity) during COVID 19.” International Journal of Research in Pharmaceutical Sciences 11, no. Special Issue 1 (2020): 1351-55. https://doi.org/10.26452/ijrps. v11iSPL1.3639.

COVID-19 Map [Internet]. Johns Hopkins Coronavirus Resource Center. [cited 2020 Dec 15]. Available from: https://coronavirus.jhu.edu/map.html

Dasari, Venkatesh, and Kiran Dasari. 2020 "Nutraceuticals to Support Immunity: COVID-19 Pandemic- A Wake-up Call.” JOURNAL OF CLINICAL AND DIAGNOSTIC RESEARCH. https://doi.org/10.7860/ JCDR/2020/44898.13843.

Dhok, Archana, Lata Kanyal Butola, Ashish Anjankar, Amol Datta Rao Shinde, Prakash Kesharao Kute, and Roshan Kumar Jha. 2020 "Role of Vitamins and Minerals in Improving Immunity during Covid-19 Pandemic - A Review." JOURNAL OF EVOLUTION OF MEDICAL AND DENTAL SCIENCES-JEMDS 9:2296-2300. https://doi. org/10.14260/jemds/2020/497.

Dushyant Bawiskar, Pratik Phansopkar, Ayurva Vilas Gotmare. 2020 COVID-19 Facets: Pandemics, Curse and Humanity. Int J Res Pharm Sci. 6;11(SPL1):385-90.

Feyaerts AF, Luyten W. Vitamin C as prophylaxis and adjunctive medical treatment for COVID-19? Nutr Burbank Los Angel Cty Calif https://www.ncbi.nlm.nih. gov/pmc/articles/PMC7381407/

Gaidhane S, Khatib N, Zahiruddin QS, Gaidhane A, Telrandhe S, Godhiwal P. 2020 'Depression, anxiety and stress among the general population in the time of COVID-19 lockdown: A cross-sectional study protocol.' International Journal of Research in Pharmaceutical Sciences, 11(1);360-364.

Guan W-J, Liang W-H, Zhao Y, Liang H-R, Chen Z-S, Li Y-M, et al. 2020 Comorbidity and its impact on 1590 patients with COVID-19 in China: a nationwide analysis. Eur Respir J. ;55(5).

Infusino F, Marazzato M, Mancone M, Fedele F, Mastroianni CM, Severino P, et al. 2020 Diet Supplementation, Probiotics, and Nutraceuticals in SARS-CoV-2 Infection: A Scoping Review. Nutrients. $8 ; 12(6)$.

Jachak, S., P. Phansopkar, and M. Waqar Naqvi. 2020 "Impact of Covid-19 in India, a Disastrous Pandemic Outbreak." International Journal of Research in Pharmaceutical Sciences 11:399-402. https://doi. org/10.26452/ijrps.v11iSPL1.2735.

Jayawardena R, Misra A. 2020 Balanced diet is a major casualty in COVID-19. Diabetes Metab Syndr.14(5):1085-6.

Joseph, M.B., S. Pohekar, A. Raut, and M. Patil. 2020 "The Palliative Care and Covid-19 Pandemic." International Journal of Research in Pharmaceutical Sciences 11: 618-22. https://doi.org/10.26452/ijrps. v11iSPL1.2861.

Joshi, K., N. Acharya, S. Acharya, and S. Joshi. 2020 "A Grave Situation with COVID in the Gravid: A Narrative Review." International Journal of Research in Pharmaceutical Sciences 11:496-99. https://doi. org/10.26452/ijrps.v11iSPL1.2837.

Khatib, M.N., S. Gaidhane, M. Khatib, M. Ahmed, A. Gaidhane, and Z.Q. Syed. 2020 "SARS-CoV and SARSCoV-2: Similar Viruses with Different Trajectories." Wutan Huatan Jisuan Jishu 16: 544-48.

Kolhe, Seema, Minal Dambhare, Priya Dhankasar, Pallavi Dhole, Ashwathy Nair, and Priya Rewatkar. 2020 "Home Remedies During Covid Pandemic Lockdown." JOURNAL OF RESEARCH IN MEDICAL AND DENTAL SCIENCE 8:103-7.

Lakhkar, B.B., B. Guru, S. Damke, and S. Damke. 2020 "Most Susceptible Duo in COVID-19 Crisis: A Literature Review." Perinatology 21:112-23.

Latchoumi, T.P., Ezhilarasi, T.P. and Balamurugan, K., 2019. Bio-inspired weighed quantum particle swarm optimization and smooth support vector machine ensembles for identification of abnormalities in medical data. SN Applied Sciences, 1(10), pp.1-10.

Malek Mahdavi A. 2020 A brief review of interplay between vitamin $\mathrm{D}$ and angiotensin-converting enzyme 2: Implications for a potential treatment for COVID-19. Rev Med Virol.30(5):e2119. 
Pizzini A, Aichner M, Sahanic S, Böhm A, Egger A, Hoermann G, et al. Impact of Vitamin D Deficiency on COVID-19-A Prospective Analysis from the CovILD Registry. Nutrients [Internet]. https://www.ncbi.nlm. nih.gov/pmc/articles/PMC7551662/

Rajput, D.S. 2020 “Evolution, Ayurveda, Immunity, and Preventive Aspects for Emerging Infectious Diseases Such as COVID-19.” International Journal of Research in Pharmaceutical Sciences 11: 86-93. https://doi. org/10.26452/ijrps.v11iSPL1.2227.

Rathi, B., R. Rathi, V. Ade, and A. Pargaonkar. "Chyavanprash: Choice of Drug for Immunity Boosting and Health Supplements during OVID-19 Pandemic." International Journal of Research in Pharmaceutical Sciences 11, no. Special Issue 1 (2020): 1346-50. https:// doi.org/10.26452/ijrps.v11iSPL1.3638.

Rishi P, Thakur K, Vij S, Rishi L, Singh A, Kaur IP, et al. 2020 Diet, Gut Microbiota and COVID-19. Indian J Microbiol. 28;1-10.
Sahoo H, Mandal C, Mishra S, Banerjee S. 2020 Burden of COVID-19 pandemic in India: Perspectives from Health Infrastructure. medRxiv https://www.medrxiv. org/content/10.1101/2020.05.26.20113456v1

Sundararaman A, Ray M, Ravindra PV, Halami PM. 2020 Role of probiotics to combat viral infections with emphasis on COVID-19. Appl Microbiol Biotechnol. 104(19):8089-104.

Wang B, Li R, Lu Z, Huang Y. 2020 Does comorbidity increase the risk of patients with COVID-19: evidence from meta-analysis. Aging. 2020 Apr 8;12(7):604957.

WHO Coronavirus Disease (COVID-19) Dashboard. https://covid19.who.int

WHO Director-General's opening remarks at the media briefing on COVID-19 - 7 September 2020 https://www. who.int/director-general/speeches/detail/who-directorgeneral-s-opening-remarks-at-the-media-briefing-oncovid-19---7-september-2020 